\title{
Investigating the Phytochemical, Antibacterial and Antifungal Effects of Thymus Vulgaris and Cuminum Cyminum Essential Oils
}

\author{
Soghra Valizadeh (MSc) \\ Department of Food Hygiene\& Quality \\ Control, Faculty of Veterinary \\ Medicine, Urmia Univer \\ sity, Urmia, Iran \\ Razzagh Mahmoudi (PhD) \\ Department of Health and Food Safety, \\ School of Public Health, Qazvin \\ University of Medical Sciences, \\ Qazvin, Iran \\ Tayebeh Fakheri (DVM) \\ Faculty of Veterinary Medicine, \\ University of Tabriz, Tabriz, Iran \\ Farzad Katiraee (PhD) \\ Department of Pathobiology, Faculty \\ of Veterinary Medicine, University of \\ Tabriz, Tabriz, Iran \\ Vahideh Rahmani (DVM) \\ Department of Clinical Sciences, \\ Faculty of Veterinary Medicine, \\ University of Tehran, Tehran, Iran \\ Corresponding author: Razzagh \\ Mahmoudi \\ E-mail: r.mahmodi@yahoo.com \\ Tel: +899127868571 \\ Address: Department of Health and \\ Food Safety, School of Public Health, \\ Qazvin University of Medical \\ Sciences, Qazvin, Iran
}

Received : 19 Aug 2014

Revised: 07 Jan 2015

Accepted: 13 Jan 2015
Abstract
Background and Objective: Phytochemical and antimicrobial properties of Thymus
vulgaris and Cuminum Cyminum essential oils (Eos) against foodborne pathogens and
Candida species in vitro were assessment.
Methods: The E0s was extracted using a Clevenger apparatus. Analysis of the E0
constituents was performed using gas chromatography-mass spectrophotometry. The
antibacterial activity of E0s against Bacillus cereus, Listeria monocytogenes, Escherichia coli
and Salmonella typhimurium were evaluated in agar culture medium. The minimum
inhibitory concentration (MIC) of these E0s against fungal strains of Candida albicans, C.
tropicalis, C. parapsilosis and C. dubliniensis was measured.
Results: Thymol (64.45\%) and cuminaldehyde (29.02\%) were the main components of
the Thymus vulgaris and Cuminum Cyminum E0s, respectively. The largest inhibition zone
diameter in the Thymus vulgaris and Cuminum Cyminum Eos in the agar disk diffusion
method was related to B.cereus with 30 and 21 mm diameter, respectively. The largest
growth inhibition zone diameter by the Thymus vulgaris E0 in the well diffusion method
was 21 mm and against B.cereus. The MIC of Thymus vulgaris E0 in the microdilution
method was 0.09\% against all the four Candida strains. The MIC of Cuminum Cyminum E0
against strains of C. albicans and C. tropicalis was $0.39 \%$, while it was found as 0.19\%
against C. parapsilosis and C. dubliniensis.
Conclusion: In this study, Cuminum Cyminum and Thymus vulgaris Eos show suitable
inhibitory effects against the growth of pathogenic bacteria and Candida species. This study
has raised the possibility of using these E0s as an alternatives chemical preservative in the
foods.
Keywords: essential oil, Cuminum cyminum, Thymus vulgaris, antibacterial, antifungal. 


\section{INTRODUCTION}

Inappropriate use of antibiotics such as non-compliance of patients with required dosage or overuse leads to the development of bacterial resistance to antibiotics (1). Essential oils are volatile oily liquids with antimicrobial properties. Numerous studies have been performed on their use in controlling the growth of foodborne pathogenic bacteria and spoilage bacteria $(2,3)$. Since essential oils are used in many types of foods to create exquisite tastes, the simultaneous presence of their antimicrobial properties may encourage their further usage (4). Thymus is a main genus of the Lamiaceae family which includes about 215 species of perennial herbaceous plants and small shrubs. Overall, 14 species of this genus grow in different parts of Iran (5). It is also used as a medicinal herb for strengthening the nervous system, treatment of depression and insomnia, and has antimicrobial, anti-parasitic and anti-fungal properties. When boiled, it is also used as an anti-flatulence, antispasmodic, antitussive and to control common cold and improve digestion (6). Thymus vulgaris is a native plant of Iran and its vegetative tissue contains antimicrobial active substance. Thymol and Carvacrol are the main components of essential oils of this family. This plant also contains Tannin, Flavonoids, Saponin and bitter substances $(7,8,9)$. Cuminum cyminum is an annual herbaceous plant, delicate and aromatic member of the Apiaceae family (10). This plant is native to the Middle East, especially South East of Iran and its wild form grows in Kerman province. Sabinene, flavonoids, polysaccharides, coumarin, cuminaldehyde, pinene and terpinene are some of the key and major compounds of this plant (11). Cuminum cyminum is used in treatment of various diseases as an anticonvulsant, anti-epileptic, Stomach-strengthener, diuretic, anti-flatulence, anti-dyspepsia and sweating stimuli, as well as being useful for diabetics (12). The aim of this study was to determine the chemical composition and evaluate the antimicrobial activity of essential oils of Thymus vulgaris and Cuminum cyminum against foodborne pathogens using disc assay and agar well diffusion assay. Moreover, microdilution method was used to assess the antifungal efficacy of the essential oils and determine their minimum inhibitory concentration (MIC) against the Candida species, as the most common cause of fungal infections in humans, especially in immunocompromised patients.

\section{MATERIAL AND METHODS}

In order to extract the essential oils, Thymus vulgaris and dried seed of Cuminum cyminum were purchased. The scientific name of the plants was confirmed by the herbarium center of faculty of Pharmacy, Tabriz University, Iran. The plants were fully grinded (aerial parts of Thymus vulgaris and Cuminum cyminum seed), and their essential oil were obtained by 3 hour water distillation and extraction using a Clevenger apparatus. Dewatering was done using dried sodium sulfate and the obtained oil was kept in dark glass containers at refrigerator temperature (13). The prepared samples were first injected into a gas chromatograph and the optimum temperature of column for the separation of essential oils' constituents was obtained. Also, the percentage of constituents for each essential oil sample was calculated. The essential oil was injected to the gas chromatograph, attached to a mass spectrograph and the mass spectra of the compounds were achieved. Identification of essential oil compounds was performed using evaluation of mass spectrum for each essential oil components and their comparison with the reference spectra. In this study, a Agilent 6890 gas chromatograph with capillary column of $30 \mathrm{~m}$ length, an inner diameter of $0.25 \mathrm{~mm}$ and $0.25 \mu \mathrm{m}$ thick inner layer of HP-5MS type. The column temperature program started as 70 ${ }^{\circ} \mathrm{C}$ for 2 minutes, then the temperature was increased to $220{ }^{\circ} \mathrm{C}$ with rate of $15{ }^{\circ} \mathrm{C}$ per minute and then it was increased to $300{ }^{\circ} \mathrm{C}$ for 2 minutes. Injection chamber temperature was $290{ }^{\circ} \mathrm{C}$ and helium was used as the carrier gas with a flow rate of $0.8 \mathrm{ml} / \mathrm{min}$. Agilent 5973 mass spectrometer with ionization energy of $70 \mathrm{eV}$ was used and electron ionization source detector temperatures was $220{ }^{\circ} \mathrm{C}$ (14). The antimicrobial activity of Cuminum cyminum and Thymus vulgaris essential oils was evaluated against two Gram-positive bacteria (Bacillus cereus ATCC 11178 and Listeria monocytogenes ATCC 19118) and two Gramnegative bacteria (Escherichia coli ATCC 43894 and Salmonella typhimurium ATCC 13311). Also, the activity of essential oils against fungal strains of Candida albicans ATCC 10231, $C$. tropicalis ATCC 750, $C$. parapsilosis ATCC 22019 and C. dubliniensis 
CD 36 was determined. The Selection of bacterial species was based on their importance in food contamination and food poisoning among humans. Moreover, Candida was used in this study due to its importance as the most common cause of fungal infection in humans, and particularly immunocompromised patients. Bacterial suspension of each bacteria was obtained from the Department of Microbiology, Faculty of Veterinary Medicine, University of Tabriz and then prepared separately $(0.5$ McFarland equivalent). In the disk diffusion method, 100 $\mu \mathrm{l}$ of the second 24-hour bacterial culture (containing $10^{8} \mathrm{CFU} / \mathrm{ml}$ ) were cultured in nutrient agar. The essential oils were dissolved in 10\% dimethyl sulfoxide (DMSO) solution, at the highest concentrations used $(400 \mu \mathrm{l} / \mathrm{ml})$. Four serial dilutions of the essential oils were prepared in the range of 25 to $400 \mu 1$ and then $35 \mu \mathrm{l}$ of the prepared serial dilutions were added to $6 \mathrm{~mm}$ sterile paper discs, which were transferred to plates after drying. Plates were incubated for 24 hours and the inhibition zone diameter was measured. All the experiments were done in triplicate (15). Next, $100 \mu \mathrm{l}$ of the refreshed bacterial cultures containing $10^{8}$ $\mathrm{CFU} / \mathrm{ml}$ were cultured on nutrient agar using sterile swabs. Then, wells with a diameter of 6 $\mathrm{mm}$ were created using a sterile tool on the agar surface. Afterwards, $40 \mu \mathrm{l}$ of each concentration of the essential oils were inoculated in the related well. The plates were incubated for 24 hours at $37{ }^{\circ} \mathrm{C}$. Finally, bacteria growth inhibition zone diameter was measured. These experiments were not performed in triplicate $(16,17)$. Fungi were cultured in the Potato (potato extract) dextrose agar (Merck, Germany) containing chloramphenicol and incubated for 5 days at $28{ }^{\circ} \mathrm{C}$. Broth microdilution and serial dilutions in 96-well plates were used to investigate the antifungal effects of Thymus vulgaris and Cuminum cyminum essential oils according to the recommended method of CLSI (M27-A2). A fungal suspension was prepared in $5 \mathrm{ml}$ of $0.85 \%$ sterile physiological saline, containing Tween $80(1 \%)$ of the fungus spores grown on Potato dextrose agar, so that the resulted suspension had 78 to $90 \%$ dispersion at wavelength of $520 \mathrm{~nm}$ (equivalent to $1 \times 10^{6}$ $5 \times 10^{6} \mathrm{CFU} / \mathrm{ml}$ ). The resulting suspension was first diluted $1 / 100$ and then $1 / 20$ to be used for the experiment (equivalent to $0.5 \times 10^{3}-2.5 \times$
$10^{3} \mathrm{CFU} / \mathrm{ml}$ yeast cells). An initial concentration of the essential oils was prepared as $100 \mu \mathrm{l}$ of essential oils in one $\mathrm{ml}$ of $10 \%$ DMSO, then dissolved in the RPMI1640 medium and became sterile using a filter. About $100 \mu \mathrm{l}$ of the twice concentration (2X) of RPMI1640 medium containing Lglutamine in $0.165 \mathrm{M}$ MOPS buffer $(\mathrm{pH}=7)$ were added to each well of the 96-well plate. This double concentration was achieved by adding the following compounds to the optimum concentration (1X). Then, $100 \mu \mathrm{l}$ of the prepared solution was added to the first well of each row. Later, $100 \mu$ of the first well was transferred to the next well until the last well of the plate. Finally, $100 \mu \mathrm{l}$ of the fungal suspension containing $0.5 \times 103-2.5 \times 103$ $\mathrm{CFU} / \mathrm{ml}$ yeast were added to all wells of the microplate. The microplate was incubated for 48 hours at $37{ }^{\circ} \mathrm{C}$. After this period, the resulting turbidity was evaluated. The concentration of essential oils that reduced the fungal growth to $80 \%$ was considered as the MIC for fungi. All the experiments were performed in triplicate (18).

\section{RESULTS}

As seen in Table 1, in the essential oil of Thymus vulgaris, thymol (64.45\%), gammaterpinene $(9.22 \%)$ and p-cymene $(6.18 \%)$ were found as the main compounds. While, cuminaldehyde $(29.02 \%)$, alpha-terpinene (20.7\%), gamma-terpinene $(12.94 \%)$, gammaterpinene $3 \mathrm{~L}(8.9 \%)$ and p-cymene $(8.55 \%)$ were identified as the major compounds in the essential oil of Cuminum cyminum. Table 3 shows the inhibitory effects of the essential oil of Thymus vulgaris and Cuminum cyminum at different concentrations in the disk diffusion method. Accordingly, the maximum diameter of the inhibition zone of Thymus vulgaris essential oil was measured against $B$. cereus $(30 \mathrm{~mm})$. The maximum size of the inhibition zone of Cuminum cyminum in this method was also recorded against $B$. cereus $(21 \mathrm{~mm})$. Table 2 shows the inhibition zone diameter of different concentrations of the two essential oils using the agar well diffusion method. The largest inhibition zone of Thymus vulgaris was recorded against $B$. cereus $(21 \mathrm{~mm})$. The MIC of Thymus vulgaris was lower compared to Cuminum cyminum, which indicates the high antifungal activity of Thymus vulgaris essential oil. 
Table 1- The main components of Cuminum cyminum and Thymus vulgaris

\begin{tabular}{ccc}
\hline Compounds & Cuminum cyminum & Thymus vulgaris \\
\hline Thymol & & 64.45 \\
Gamma-terpinene & 12.94 & 9.22 \\
P-cymene & 8.55 & 6.18 \\
Carvacrol & - & 2.82 \\
Beta-caryophyllene & - & 2.14 \\
Borneol & - & 2.04 \\
Linalool & - & 1.28 \\
& & \\
Cuminaldehyde & 29.02 & - \\
Alpha-terpinene & 20.7 & - \\
Gamma-terpinene 3 L & 8.9 & - \\
cis-dihydrocarvone & 4.45 & - \\
Beta-pinene & 3.3 & - \\
Myrcene & 1.1 & - \\
1,8-cineol & 0.84 & - \\
\hline
\end{tabular}

Table 2-The growth inhibition zone diameter $(\mathrm{mm})$ of the essential oil of Thymus vulgaris and Cuminum cyminum at different concentrations, using agar disk and well diffusion methods

\begin{tabular}{|c|c|c|c|c|c|c|c|c|c|c|c|c|c|c|c|c|c|c|}
\hline & \multicolumn{8}{|c|}{ Essential oil of Cuminum cyminum $(\mu \mathrm{g} / \mathrm{ml})$} & \multicolumn{9}{|c|}{ Essential oil of Thymus vulgaris $(\mu \mathrm{g} / \mathrm{ml})$} & \multirow[b]{3}{*}{ Method } \\
\hline 25 & & 50 & & 100 & & 200 & & 25 & & 50 & & 100 & & 200 & & 400 & & \\
\hline well & Disk & well & Disk & well & Disk & well & Disk & well & Disk & well & Disk & well & Disk & well & Disk & well & Disk & \\
\hline * & 8 & - & 9 & 13 & 10 & 14 & 11 & - & 14 & 12 & 16 & 15 & 20 & 18 & 21 & * & 23 & S. typhimurium \\
\hline * & - & 10 & 8 & 12 & 8 & 13 & 9 & - & 10 & 11 & 16 & 15 & 18 & 17 & 19 & * & 21 & E. coli \\
\hline * & 8 & * & 9 & * & 14 & $*$ & 21 & 13 & 10 & 15 & 12 & 17 & 26 & 21 & 28 & * & 30 & B. cereus \\
\hline
\end{tabular}

No inhibition zone : -

Not done : *

Table 3-The MIC of essential oils of Thymus vulgaris and Cuminum cyminum against Candida species using the broth microdilution method

\begin{tabular}{ccc}
\hline $\begin{array}{c}\text { Essential oil of } \\
\text { Cuminum cyminum } \\
(\%)\end{array}$ & $\begin{array}{c}\text { Essential oil of Thymus } \\
\text { vulgaris (\%) }\end{array}$ & Candida species \\
\hline 0.39 & & \\
0.39 & 0.09 & albicans \\
0.19 & 0.09 & tropicalis \\
0.19 & 0.09 & parapsilosis \\
dubliniensis \\
\hline
\end{tabular}




\section{DISCUSSION}

In this study, chemical composition and antimicrobial effect of essential oils of Thymus vulgaris and Cuminum cyminum were evaluated. Cuminaldehyde (29.02\%) and alpha-terpinene $(20.7 \%)$ were the major components of the Cuminum cyminum essential oil. Results of evaluating the chemical composition of Cuminum cyminum seed in the present study are somewhat consistent with other studies. In most studies, compounds such as cuminaldehyde, alphaterpinene, beta-pinene, gamma-terpinene, cymene and P-menthane were found as the major components of this essential oil. Cuminaldehyde $(30.2 \%)$ and p-cymene (14.13\%) were found as the main components of the essential oil of Cuminum cyminum in the study of Aroojalian et al., which is largely consistent with the present study (19). In Attaur-Rahman et al. study, 20 compounds were identified the essential oil of Cuminum cyminum where cuminaldehyde, p-cymene, beta-pinene and gamma-terpinene were found as the main compounds (20). This essential oil is composed of pinene, alpha-terpineol, apigenin and flavonoids, which have antimicrobial properties in addition to a particular aroma. These compounds often exert their antimicrobial effect by creating pores in the cell membrane of Gram-positive bacteria and destructing the outer membrane of Gramnegative bacteria (21). Iacobellis et al. showed that the presence of high levels of cuminaldehyde $(16.1 \%)$ in this essential oil can have antibacterial activity against certain Gram-negative and Gram-positive bacteria (22). Thymol (64.45\%) was found as the major constituent of Thymus vulgaris essential oil in this study, which is largely consistent with the results of other similar studies $(23,24)$. In these investigations, thymol and p-cymene were the major compounds in the essential oil of Thymus vulgaris. In Moghtader study to assess the antifungal activity of Thymus vulgaris essential oil, thymol and p-cymene were found as the major compounds. The antifungal activity of this essential oil in high concentrations was more than Streptomycin sulfate. It is reported that thymol has high fungicidal activity and its antimicrobial activity is due to its phenolic structure. Also, the inhibitory effect of thymol was almost thrice the effect of Thymus vulgaris essential oil (25). The constituents of certain species of plants may differ compared to the same species in different regional conditions. This could be due to differences in harvesting season, oil extraction time, geographical areas and even different parts of plants (21). In this study, essential oil of Thymus vulgaris and Cuminum cyminum had the greatest impact against $B$. cereus in the disk and well diffusion methods. B. cereus and $L$. monocytogenes growth inhibition zone diameter was larger compared with the Gram-negative bacteria that were studied. In general, Gram-positive bacteria show greater sensitivity to plant extracts and essential oils in comparison with Gram-negative bacteria (26). The increase in the antimicrobial activity of the essential oils by increasing their concentration was evident. In study of Daneshmadi et al., the antibacterial activity of Cuminum cyminum essential oil against several bacterial strains was assessed. Standard strains of B. cereus, B. subtilis, $S$. aureus, E. coli and Shigella flexneri showed the greatest sensitivity to the essential oil's constituents, but the sensitivity of Enterococcus faecalis, S. typhimurium and Pseudomonas aeruginosa strains was not significant (27). In another study, the antimicrobial effect of Cuminum cyminum seed against $E$. coli and $S$. typhimurium was demonstrated (28). Results of Mahmoudi et al. study showed the relatively good antibacterial activity of Cuminum cyminum essential oil, with the highest activity observed against $S$. aureus. However, S. typhimurium and E. coli were the most resistant bacteria against this essential oil (29). As demonstrated by the results of the present study, the antibacterial effect of essential oils used against Grampositive bacteria is more than Gram-negative bacteria. Ranjbarian et al. studied the antibacterial effects of four plant extracts including Cuminum cyminum, on Helicobacter pylori using disk diffusion method and reported the inhibitory effect of cumin against this bacterium (30). In a study conducted by Yano et al., the antimicrobial effect of Cuminum cyminum on growth of Vibrio parahemolyticos was assessed and its inhibitory effect at concentration of $0.02 \%$ was confirmed (31). Derakhshan et al. also investigated the antimicrobial effect of this essential oil on growth of Klebsiella pneumoniae and reported its inhibitory effect at concentration of $0.03 \%$ (32). In a study, the 
antimicrobial activity of Cuminum cyminum essential oil against foodborne pathogens such as L. monocytogenes and E. coli are welldemonstrated (33). In study of Pajohi et al., the main constituents of this essential oil and its antibacterial effect at different concentrations against $B$. cereus were investigated in food models kept at different temperatures. The main compounds were benzaldehyde (27.18\%) and phenyl-propanol (17.5\%), respectively. Storage temperature had a significant effect on the growth of bacteria in the samples. So that the temperature of $10{ }^{\circ} \mathrm{C}$ significantly reduced the growth of bacteria compared to $25{ }^{\circ} \mathrm{C}$. The high concentration of the essential oil significantly inhibited the growth of bacteria in the samples (34). Nowadays, Thymus vulgaris is considered as a plant with high antimicrobial effects. The antibacterial, antifungal and antiviral activities of this plant have been demonstrated. High antimicrobial activity of Thymus vulgaris essential oil and its major constituents such as thymol and carvacrol, against $S$. aureus, S. epidermidis, $E$. faecalis, B. cereus, V. cholerae, E. coli, S. typhimurium and many other microorganisms have been reported (25). The results of Haghighi et al. study on essential oils of Thymus vulgaris, parsley, Cuminum cyminum and black cumin on $C$. albicans showed that, the leaves of Thymus vulgaris have the highest inhibitory effect on this fungus. Carvacrol is among the main constituents of Thymus vulgaris, and the antifungal properties of this plant can be attributed to this compound (35).
Sokovic et al. studied the antifungal activity of essential oil of Thymus vulgaris on Dermatophytosis in animal models and reported its positive effect (9). Kon et al. study on the antibacterial effect of this essential oil also showed its good growth inhibitory effect against E. coli and S. aureus (33). Kačániová et al. study also showed the high antibacterial activity of this essential oil against $E$. coli and B. cereus (36). The present study showed that the MIC of essential oil of Thymus vulgaris is lower than the essential oil of Cuminum cyminum, which indicates higher antifungal activity of Thymus vulgaris. Kalemba et al. attributed the high antimicrobial activity of plants to their high levels of phenolic compounds. Accordingly, the high activity of Thymus vulgaris which contains high levels of phenolic compounds is justified (37).

\section{CONCLUSION}

Essential oils of Cuminum cyminum and Thymus vulgaris have antibacterial and antifungal properties with different effects against various species. This study has raised the possibility of using these essential oils as suitable antimicrobial compounds and alternatives for chemical preservatives in the food industry.

\section{ACKNOWLEDGEMENT}

The authors would like to thank the Department of Microbiology, Faculty of Veterinary Medicine, University of Tabriz for their cooperation in this study.

\section{CONFLICT OF INTEREST}

Therer are no conflicts of interest. 


\section{REFERENCES}

1. Kotzé MM, Eloff JN. Extraction of antibacterial compound from Combretum microphyllum(Combretaceae). South African Journal of Botany. 2002; 68(1): 62-67.

2. Hao YY, Brackett RE, Doyle MP. Efficacy of plant extracts in inhibiting Aeromonas hydrophila and Listeria monocytogenes in refrigerated cooked poultry. Food microbiology. 1998; 15: 367-78.

3. Palmer S, Stewart J, Fyfe L. The potential application of Plant essential oils as natural food preservatives in soft cheese. Food microbiology. 2001; 18(4): 463-70.

4. Ghahreman A. Flora of Iran. Iran: Research Institute of Forests and Rangelands. 1986; 102-5. VazquezBoland JA, Kuhn M, Berche P, Chakraborty T, Dominguez-Berna,1 G, Goebel $\mathrm{W}$, et al. Listeria pathogenesis and molecular virulence determinants. Clinical microbiology reviews. 2001; 14: 584-640. doi: 10.1128/CMR.14.3.584-640.2001.

6. Gandhi M, Chikindas ML. Listeria: a foodborne pathogen that knows how to survive. International journal of food microbiology. 2007; 113(1): 1-15.

7. Adwan G, Abu-Shanab B, Adwan K, Abu- Shanab F. Antibacterial effects of nutraceutical plants growing in Palestine on Pseudomonas aeruginosa. Turkish Journal of Biology. 2006; 30(4): 239-42.

8. Imelouane B, Amhamdi H, Wathelet JP, Ankit M, Khedid K, El Bachiri A. Chemical Composition and antimicrobial Activity of Essential Oil of Thyme (Thymus vulgaris) from Eastern Morocco. International journal of agriculture and biology. 2009; 11(2): 205-8.

9. Sokovic M, Glamoclija J, Cirić A, Kataranovski, D, Marin PD, Vukojević J, et al. Antifungal activity of the essential oil of Thymus vulgaris L. and thymol on experimentally induced dermatomycoses. Drug development and industrial pharmacy. 2008; 34(12): 1388-93.

10. Azimzadeh M. Genetic assessment of Iranian Bunium persicum Boiss using ITS. MSc thesis. University of Tehran. 2009.

11. Demirci F, Guven K, Demirci B, Dadandi MY, Baser KHC. Antibacterial activity of two Phlomis essential oils against food pathogens. Food Control. 2008; 19(12): 1159-64.

12. Evanse W, Trease C and Evan S. Pharmacognosy. $14^{\text {th }}$ ed. London. Saunders Company Ltd. 1996; 267-268.

13. Jaymand K, Rezayi M. Distillation apparatus, test methods and criteria to prevent the decomposition of oil. $1^{\text {st }}$ ed. Herbal plants association. Tehran, Iran. 2006; 105107.[Persian]

14. Akhondzadeh Basti A, Misaghi A, Khaschabi D. Growth response and modeling of the effects of Zataria multiflora Boiss. Essential oil, pH and temperature on Salmonella typhimurium and Staphylococcus aureus. LWT- Food Science and Technology. 2007; 40(6): 97381. doi:10.1016/j.lwt.2006.07.007.

15. Mehani M, Ladjel S. Antimicrobial effect of essential oils of the plant Eucalyptus camaldulensis on some pathogenia bacteria. International Proceedings of Chemical, Biological \& Environmental Engineering. 2011; 24: 212-216.
16. Igbal A, Beg AZ. Antimicrobial and phytochemical studies on 45 Indian medicinal plants against multi-drug resistant human pathogens. Journal of ethnopharmacology. 2001; 74 (2): 113-123.

17. Mohsen Nezhad F, Zeighami H, Mota A, Sattari M, Yadegar A. Antibacterial activity of Eukalyptus extracts on methicillin resistance Staphylococcus aureus. Research Journal of Biological Sciences. 2009; 4(8): 905-908.

18. Clinical and Laboratory Standards Institute. Reference method for broth dilution antifungal susceptibility testing of yeasts. Approved standard, $3^{\text {rd }}$ ed. CLSI document M27-A3. Clinical and Laboratory Standards Institute; Wayne, PA. 2008

19. Mahmoudi R, Kosari M, Barati S. Ferula sharifi Essential Oil: Phytochemical andBiological Properties. Journal of Biologically Active Products from Nature. 2013; 3(5\&6): 331-338.

20. Atta-ur-Rahman MI, Choudhary I, Farooq A, Ahmed A, Iqbal MZ, Demirci B, et al. Antifungal activity and essential oils constituents of some spices from Pakistan. Third International Electronic Conference on Synthetic Organic Chemistry. 1999. www/reprint.net/ecsco-3.htm.

21. Burt S. Essential oils: their antibacterial properties and potential applications in foods- a review. International journal of food microbiology. 2004; 4(3): $233-53$.

22. Iacobellis N, Lo Cantore P, Capasso F, Senatore F. Antibacterial activity of Cuminum cyminum L. and Carum carvi L. essential oils. Journal of agricultural and food chemistry. 2005; 53(1): 57-61.

23. Razzaghi-Abyaneh M, Shams-Ghahfarokhi M, Rezaee MB, Jaimand K, Alinezhad S, Saberi R, et al. Chemical composition and antiaflatoxigenic activity of Carum carvi L., Thymus vulgaris and Citrus aurantifolia essential oils. Food Control. 2009; 20(11): 1018-1024. doi:10.1016/j.foodcont.2008.12.007.

24. Lira Mota KS, Oliveira Pereira F, Oliveira WA, Oliveira Lima I, Oliveira Lima E. Antifungal Activity of Thymus vulgaris L. Essential Oil and Its Constituent Phytochemicals against Rhizopus oryzae: Interaction with Ergosterol. Molecules. 2012; 17(12):14418-14433. doi: 10.3390/molecules171214418.

25. Moghtader M. Antifungal effects of the essential oil from Thymus vulgaris $L$. and comparison with synthetic thymol on Aspergillus niger. Journal of Yeast and Fungal Research. 2012; 3(6): 83-88. DOI: 10.5897/JYFR12.023.

26. Sahin F, Karaman I, Gulluce M, Ogutcu H, Sengul M, Adiguzel A. Evaluation of antimicrobial activities of Satureja hortensis L. Journal of Ethnopharmacology. 2002; 87(1): 61-65.

27. Daneshmandi S, Soleimani N, Sattari M, Pourfathollah A. Evaluation of the drug synergistic and antibacterial effects of cuminum cyminum essential oil. Arak Medical University Journal. 2010; 13(2): 75-82 (Persian).

28. Mekawey AAI, Mokhtar MM, Farrag RM. Antitumor and Antibacterial Activities of 1-2- Ethyl, 6-Heptyl Phenol from Cuminum Cyminum Seeds. Journal of Applied Sciences Research. 2009; 5(11): 1881-8. 
29. Mahmoudi R, Ehsani, A, Zare P. Phytochemical, antibacterial and antioxidant properties of cuminum cyminum. Journal of Food Research. 2013; 22(3): 311321(Persian).

30. Ranjbarian P, Sadeghian S, Shirazi MH, Sarafnezhad A, Fazeli MR, Amin Gh. Survey of anti-bacterial effect of plant extracts (fennel-dill-caraway-cinnamon) by flow cytometry and disk diffusion. Scientific Journal of Hamadan University of Medical Sciences and Health Services. 2004; 11(3): 42-47.[Persian]

31. Yano Y, Satomi M, Oikawa H. Antimicrobial effect of spices and herbs on Vibrio parahaemolyticus. International journal of Food Microbiology. 2006; 111(1): 6-11

32. Derakhshan S, Sattari M, Bigdeli M. Effect of subinhibitory concentrations of cumin (Cuminum cyminum L.) seed essential oil and alcoholic extract on the morphology, capsule expression and urease activity of Klebsiella pneumonia. International journal of Antimicrobial Agents. 2008; 32(5): 432-6.

33. Kon K, Rai M. Antibacterial activity of Thymus vulgaris essential oil alone and in combination with other essential oils. Bioscience. 2012; 4(2): 50-56.

34. Pajohi Alamoti, MR, Tajik H, Farshid AA, Hadian M. Synergistic antibacterial activity of the essential oil of Cuminum cyminum L. seed and nisin in a food model. 2011, 110 (4): 943-951.

35. Haghigi F, Rudbar mohammadi Sh, Soleimani N, Sattari M. Evaluation of antifungal activity of essential oils of Thymus vulgaris, Petroselinum Crispum, Cuminum cyminum and Bunium persicum on candida albicans in comparison with Fluconazole. Journal of Medical Science: Pathobioligy. 2011; 14(1): 2935.[Persian]

36. Kačániová M, Vukovič N, Hleba L, Bobková A, Pavelková A, Rovná K and et al. Antimicrobial and antiradical activity of origanum vulgare $L$. and thymus vulgaris essential oils. Journal of microbiology, biothecnology and food sciences. 2012; 2(1): 263-271.

37. Kalemba D, Kunicka A. Antibacterial and antifungal properties of essential oils. Current medicinal chemistry. 2003; 10(10): 813-829. 